\title{
Report
}

\section{Control of High Power IGBT Modules in the Active Region for Fast Pulsed Power Converters}

J-M. Cravero ${ }^{1}$, F. Cabaleiro Magallanes ${ }^{1}$, R. Garcia Retegui ${ }^{2}$, S. Maestri ${ }^{2}$, G Uicich $^{2}$

1 CERN

2 Universidad de Mar del Plata, Argentina

Keywords: Pulsed power supply, particle accelerator, IGBT, current control

\begin{abstract}
At CERN, fast pulsed power converters are used to supply trapezoidal current in different magnet loads. These converters perform output current regulation by using a high power IGBT module in its ohmic region. This paper presents a new strategy for pulsed current control applications using a specifically designed IGBT driver.
\end{abstract}

Presented at:

EPE

Lille, France

September, 2013 


\title{
Control of high power IGBT modules in the active region for fast pulsed power converters
}

\author{
$\$$ Jean-Marc Cravero, \$Francisco Cabaleiro Magallanes, \\ $\dagger$ Rogelio García Retegui, †Sebastián Maestri, †Gustavo Uicich \\ + EUROPEAN ORGANIZATION FOR \\ NUCLEAR RESEARCH - C.E.R.N. \\ TE-EPC GROUP \\ 1211 Geneva 23 \\ Geneva, Switzerland \\ Phone: +41227672223 \\ Fax: +41227665300 \\ E-mail: jean-marc.cravero@cern.ch \\ fcabalei@,cern.ch \\ URL: http://www.cern.ch \\ $\dagger$ UNIVERSIDAD NACIONAL \\ DE MAR DEL PLATA \\ L.I.C. \\ Juan B. Justo 4302 \\ Mar del Plata, Argentina \\ Phone: +54 2234816600 \\ Fax: +41227668301 \\ Email: rgarcia@fi.mdp.edu.ar \\ somaestri@fi.mdp.edu.ar \\ guicich@,fi.mdp.edu.ar \\ URL: http://www3.fi.mdp.edu.ar
}

\section{Keywords}

«Pulsed power supply», «Particle accelerator», «IGBT», «Current control».

\begin{abstract}
At CERN, fast pulsed power converters are used to supply trapezoidal current in different magnet loads. These converters perform output current regulation by using a high power IGBT module in its ohmic region. This paper presents a new strategy for pulsed current control applications using a specifically designed IGBT driver.
\end{abstract}

\section{Introduction}

In the framework of particle accelerators, pulsed power converters are widely used to supply different magnet loads. Their main advantages, when compared to DC or programmed converters, are the reduced power consumption, the compactness and the reduced cooling requirement for the magnets. A family of converters, developed at CERN, provides trapezoidal current pulses using a high power IGBT module in its ohmic region to regulate the magnet current. This document will first present the ratings, topology and operating modes of these converters and, afterwards, it will focus on the control of the IGBT module itself. The behaviour of the IGBT in its active region is studied and modelled at different operating points, presenting a large variation in its static gain. The IGBT dynamic behaviour is also investigated, showing a large variation depending on the operating current and voltage. In order to mitigate these phenomena, a specific IGBT driver that operates in voltage control mode is implemented, allowing to obtain a quasi-constant closed loop static gain and the stabilization of the dynamics. Then, the associated control system that regulates the output current is analysed in detail and its digital implementation is described. Finally, experimental results are presented, pointing out the advantages of the proposed IGBT driver when compared with an open loop control one.

\section{Converter Parameters, Topology and Operation Principle}

At CERN, a type of converter has been developed to supply various magnets loads, mainly quadrupoles, with different operating currents. In these applications, the converter output current is a trapezoidal waveform, which allows short rise and fall times and precision current during the flat-top. The converter basic specifications are given in Table 1. 
TABLE I

\begin{tabular}{|l|r|}
\hline \multicolumn{1}{|c|}{ Parameter } & \multicolumn{1}{|c|}{ Value } \\
\hline Maximum output current & $350 \mathrm{~A}$ \\
\hline Maximum output voltage & $1000 \mathrm{~V}$ \\
\hline Maximum flat-top duration & from $300 \mu \mathrm{s}$ to $10 \mathrm{~ms}$ \\
\hline Maximum repetition rate & $5 \mathrm{~Hz}$ \\
\hline Current precision during flat-top & $1000 \mathrm{ppm}$ \\
\hline Input from the mains & $230 \mathrm{~V} \sim$ \\
\hline
\end{tabular}

The converter topology is based on a DC voltage source used to ramp the magnet current and a linear stage to control the current during the flat-top. This 'non-classical' topology has been adopted due to the parameters of the magnet loads that have to be powered. In these pulsed applications, the loads parameters are such as $L \frac{d i}{d t} \gg>i$. For the loads considered, the inductive part is usually in the range of a few hundred $\mu H$ up to some $m H$. For this type of magnets, the use of switch-mode power converters based on well-known topologies does not allow to obtain simultaneously a very low ripple current during the flat-top and short rise and fall times. Some additional topologies $[1,2]$ have been developed specifically for these particular fast pulsed operating modes but their complexity is often not well adapted for low power applications. The converter topology is presented in Figure 1.

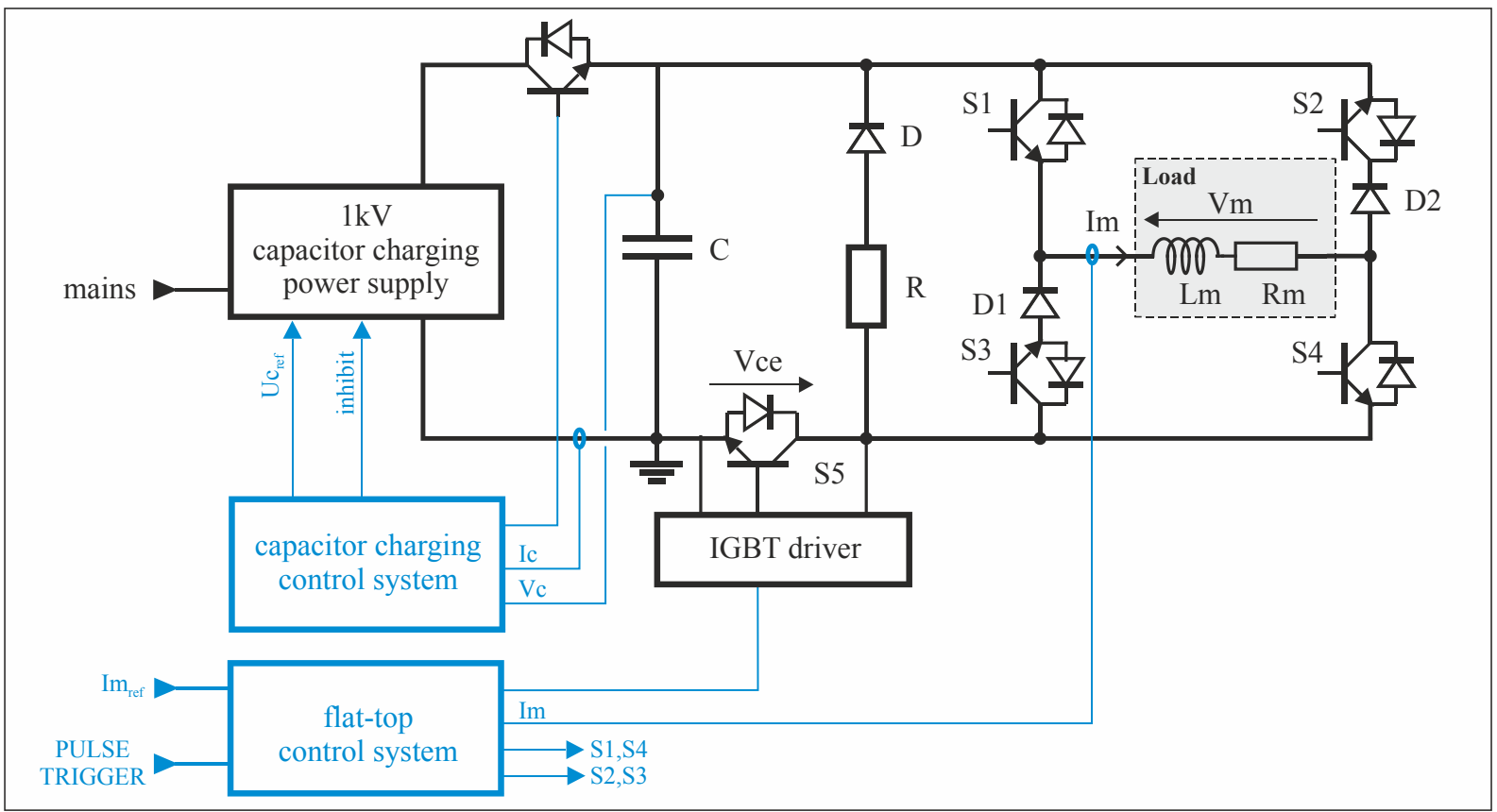

Fig. 1: Pulsed converter topology.

During the pulse, the operation of the converter can be divided in three phases, depicted in Figure 2: rise time, flat-top and fall time. The converter operation in each phase can be summarized as follows:

- Rise time: when the trigger pulse is received, $S 1$ and $S 4$ are switched on and $S 5$, the high power IGBT module, is in saturation mode. The output current ramps with a slope given by $V c / L m$ if the resistive part of the load is neglected.

- Flat-top: when the magnet current reaches its reference value $I m_{r e f}, S 5$ is operated in its active region. The output current of the converter is regulated by controlling $S 5 V_{C E}$ voltage. The branch composed by $R$ and $D$ is used to clamp the IGBT (S5) voltage with the purpose of limiting its collector voltage during transients.

- Fall time: the output current is ramped down by the turn-off of $S 1-S 4$ and the turn-on of $S 2$ $S 3$. The current flows through the anti-parallel diode of $S 5$ and the energy stored in the magnet 
load is recovered in the capacitor bank $C$. When the output current reaches zero, $D 1$ and $D 2$ are turned off and the pulse is terminated.

Typical waveforms are shown in Figure 2. During the flat-top, the voltage drop on $S 5$ is due to the discharge of the capacitor bank at constant current.

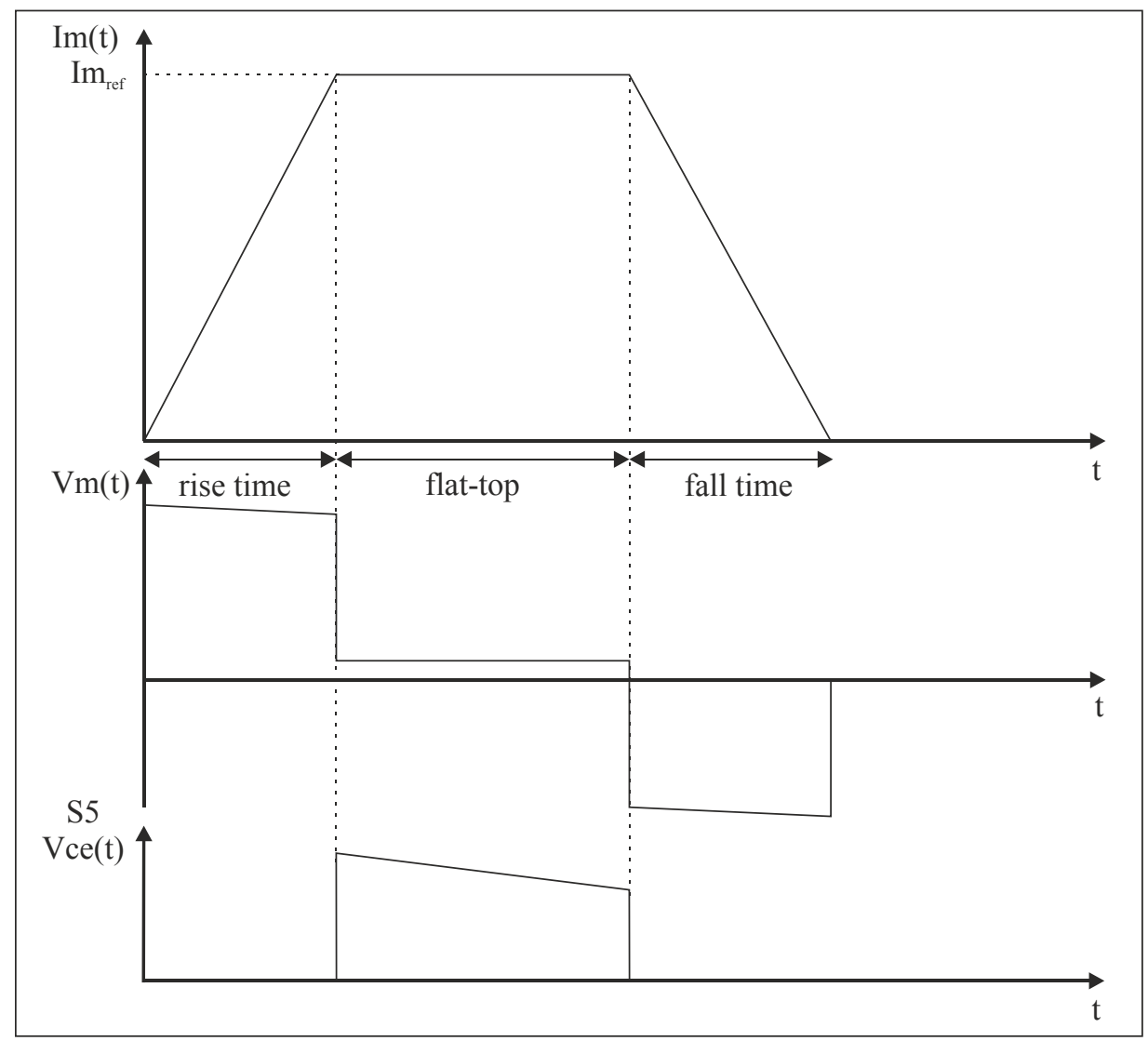

Fig. 2: Power converter typical waveforms during the current pulse.

\section{IGBT Model and Closed-loop Driver}

During the flat-top, the IGBT $S 5$ is operated in its active region in order to regulate the output current. The device selected for this application is a 2400A/1700V INFINEON IGBT module which presents low transient thermal impedance. This parameter allows a limited junction temperature excursion during the flat-top and, accordingly, no significant effect of thermal cycling as regard to the lifetime expectancy of the device. The utilization of high power IGBT modules in linear mode is not usual, although it has already been realized for different applications [3]. In order to study the converter current control system, the IGBT operation in linear mode has to be modelled. An IGBT model [4, 5, 6], where the parasitic inductances are neglected, depicted in Figure 3, has been considered.

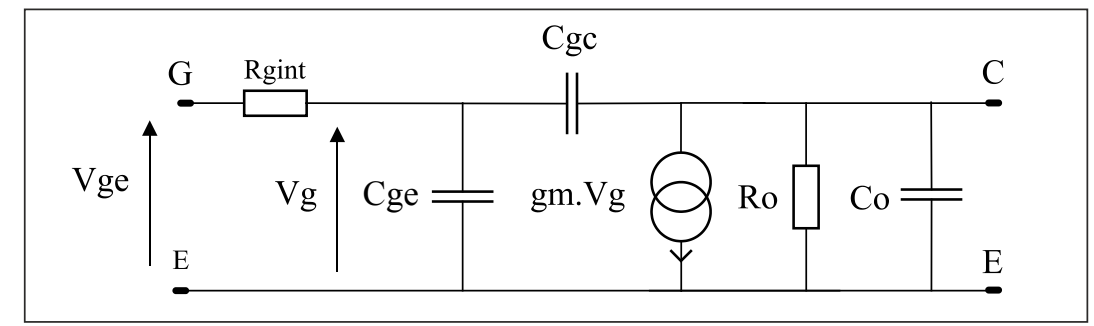

Fig. 3: Linear equivalent IGBT model.

The manufacturer datasheet does not allow to obtain the IGBT linear model parameters for different operating points and experimental measurements are required in order to obtain the static and 
dynamical parameters of the equivalent model. Results from performed measurements point out that the IGBT static parameters $\left(g_{m}\right.$ and $\left.R_{o}\right)$ are highly dependent on the collector current as shown in figure 4 . The measurements have also shown that the equivalent capacitances $\left(C_{g e}, C_{g c}\right.$ and $\left.C_{o}\right)$ are significantly varying depending on the collector current and $V_{C E}$ voltage.

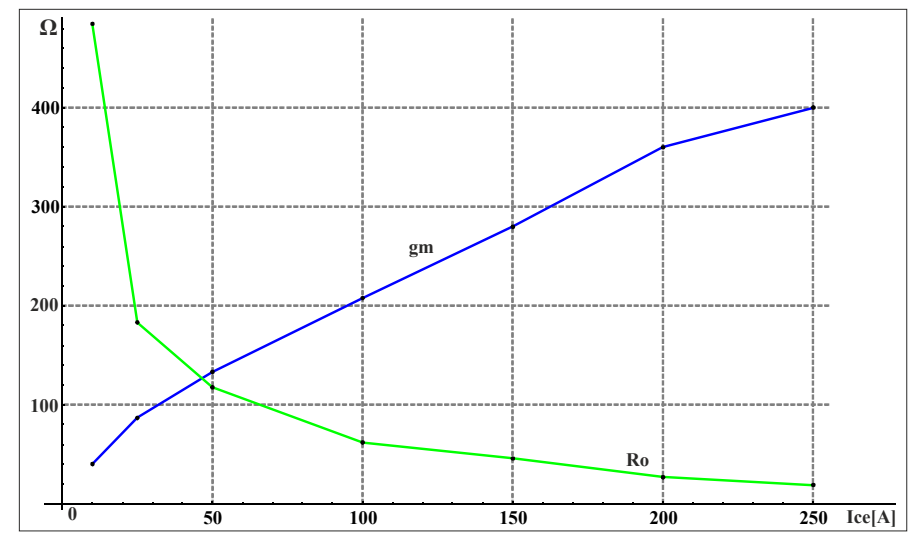

Fig. 4: Experimental measurements of the static parameters $\left(g_{m}\right.$ and $\left.R_{o}\right)$ of the IGBT model.

Taking into account these characteristics, a specific driver that linearizes the IGBT gain and dynamical behaviour by operating in voltage closed-loop has been developed and implemented. The IGBT driver architecture is shown in Figure 5.

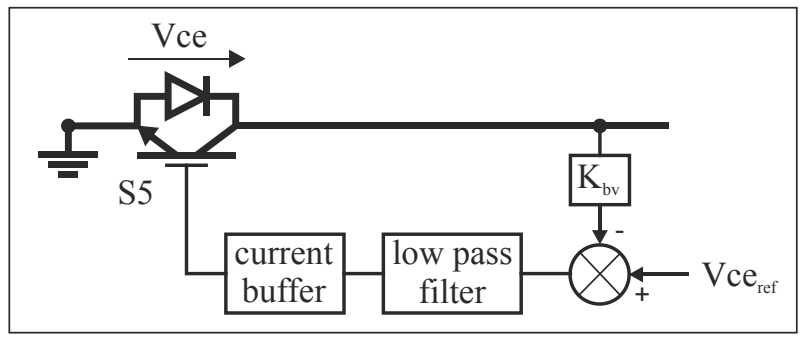

Fig. 5: IGBT driver architecture.

By using this topology for the IGBT driver, the static gain value is reduced and linearized, as shown in figure 6, allowing an efficient and simpler design of the output current control system.

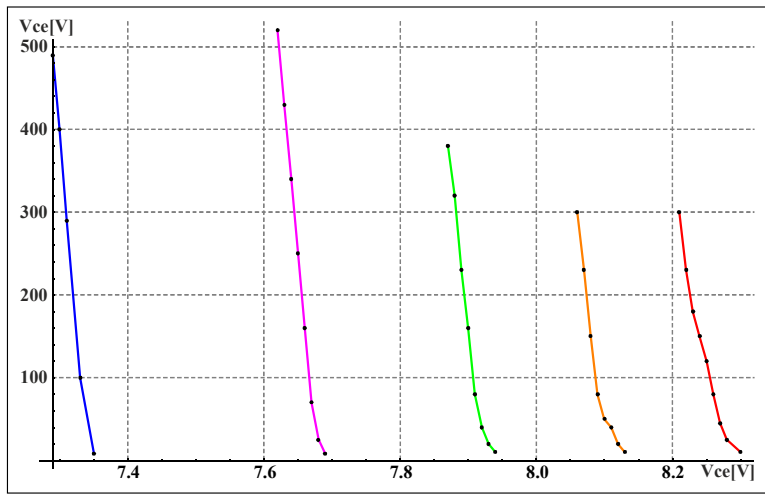

(a)

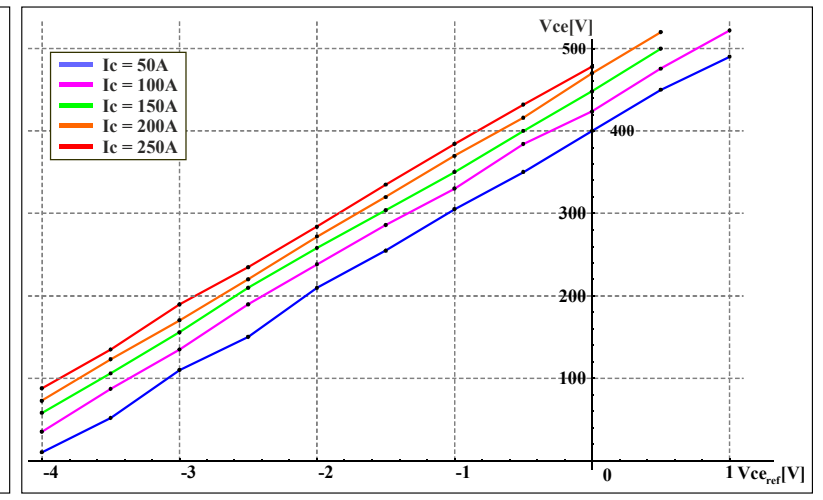

(b)

Fig. 6: Experimental measurements of the IGBT gain in open loop (a) and closed loop driver gain (b).

By controlling the IGBT voltage in closed loop, the overall system gain is significantly reduced allowing less sensitivity to perturbations and increased robustness for the current control system. Furthermore, the closed-loop gain is kept constant even with low IGBT operating currents. Figure 7 shows the implementation of the designed driver installed on the IGBT power module. 


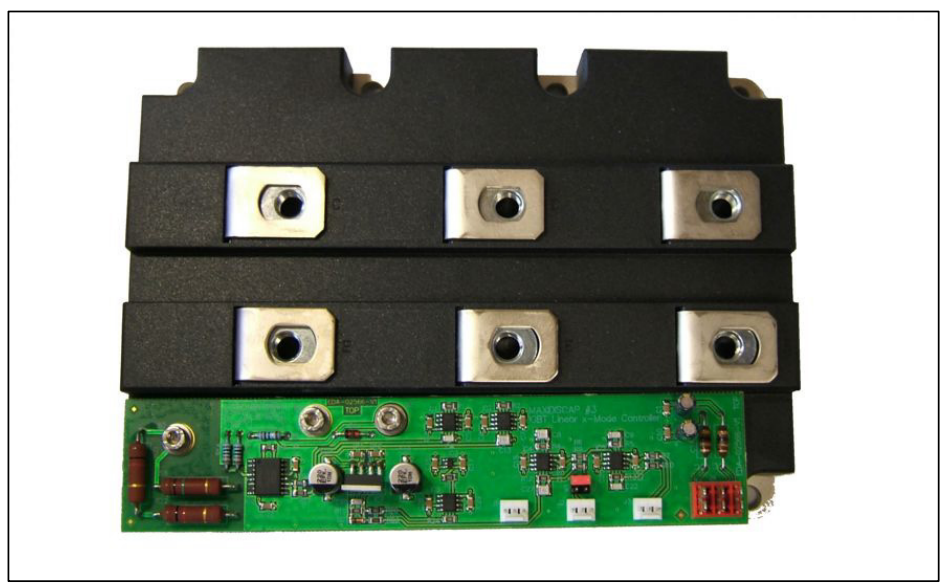

Fig. 7: Closed loop IGBT driver installed on its power module.

\section{Control Strategy}

As presented in the previous chapter, the system composed by the IGBT and its linear driver has a static gain quasi-independent of the operating conditions, particularly the IGBT collector current. Concerning the dynamics, the IGBT model shown in Figure 3 has been identified at different operating points, showing large variations of the capacitances involved. Consequently, the proper IGBT dynamics exhibit large variations according to the collector current and voltage. This behaviour is mitigated by the closed loop voltage driver, as illustrated in Figure 8, where different transient step responses for different Ic currents are shown. Even though the natural frequency seems to remain almost constant, other parameters (damping factor, delay, and specially the gain) still exhibit small variations.

The selected control strategy consists in the identification of an average transfer function and the design of a controller capable of handling the small variations of the plant.

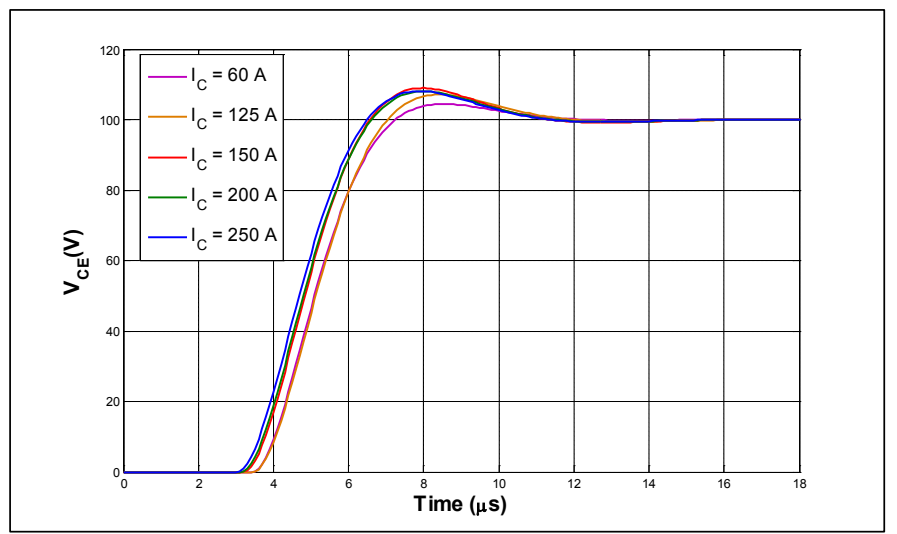

Fig. 8: IGBT and closed-loop driver step response for different $\mathrm{I}_{\mathrm{C}}$ current values.

\section{System Identification}

From Figure 8, the following average model is identified for the system composed by the IGBT module and its driver:

$$
\begin{gathered}
G_{I G B T+\text { Driver }}(s)=\frac{V c e(s)}{V c e_{\text {ref }}(s)} \\
G_{I G B T+\text { Driver }}(s)=\frac{100 e^{-s \cdot 10^{-6}}}{\left(1.06 \times 10^{-12}\right) s^{2}+\left(922 \times 10^{-9}\right) s+1}
\end{gathered}
$$


If the whole circuit during operation (see Figure 1) is considered, the system direct path transfer function is given by:

$$
\begin{gathered}
G_{p}(s)=\frac{I_{m}(s)}{V c e_{\text {ref }(s)}}=G_{I G B T+\text { Driver }}(s) \cdot G_{\text {Load }}(s) \\
G_{p}(s)=\frac{100 e^{-s \cdot 10^{-6}}}{\left(1.06 \times 10^{-12}\right) s^{2}+\left(922 \times 10^{-9}\right) s+1} \cdot \frac{C . s}{L_{m} C s^{2}+R_{m} C s+1}
\end{gathered}
$$

The system presents one zero at the origin and, if the implementation of a classical PID type controller $\mathrm{G}_{\mathrm{C}}(\mathrm{s})$ is considered, the system exhibits a non-zero steady state error for a step input reference. Therefore, the control system requires the implementation of a double integrator in order to achieve a zero steady state error. The effect of adding two integrators is a very high phase shift of $180^{\circ}$. In order to compensate this phase shift, a very important derivative action is required. Though this implementation (i.e. $\mathrm{PI}^{2} \mathrm{D}$ or PIDI) is theoretically possible, the high derivative action requires a very important filtering in order to achieve a robust and stable system response. Due to the complexity of implementing this filtering, a different regulation strategy has been selected, as explained in the following subsection.

\section{Regulation Algorithm}

Instead of measuring only the load current, the other state variable, $V c$, can also be measured and utilized in the control algorithm. A different plant is then considered, composed only by a simple $\mathrm{L}_{\mathrm{m}}$ $\mathrm{R}_{\mathrm{m}}$ load:

$$
G_{p}(s)=\frac{\left(V_{C}(s)-V_{C E}(s)\right)}{V c e_{r e f}(s)} \cdot \frac{I_{m}(s)}{\left(V_{C}(s)-V_{C E}(s)\right)}
$$

In this case, the load transfer function is given by:

$$
G_{\text {Load }}(s)=\frac{1}{L_{m} s+R_{m}}
$$

The desired $\mathrm{V}_{\mathrm{CE}}$ voltage is obtained by adding to the actuation of the controller the measurement of $\mathrm{V}_{\mathrm{C}}$ using a feed-forward branch. The adopted control strategy is illustrated in Figure 9.

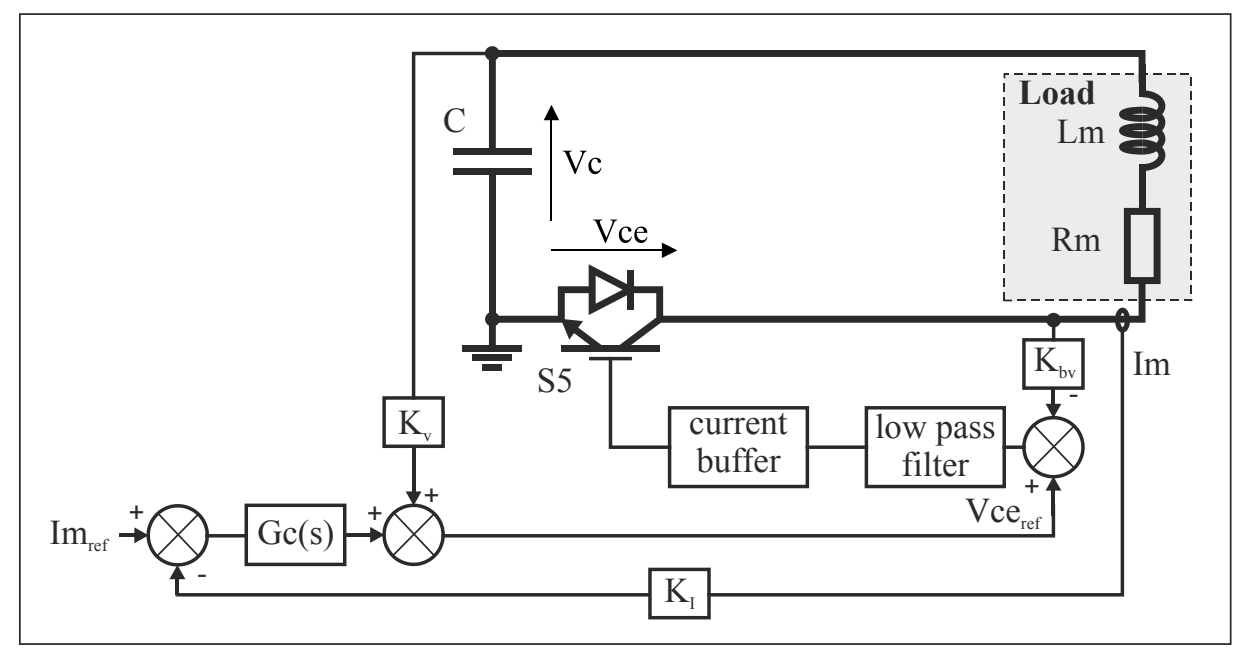

Fig. 9: Closed-loop magnet current control system with feedforward.

Considering this alternative control strategy, a simple PI controller can be implemented to regulate the magnet current and obtain a zero steady state error. With the purpose of illustrating the simplicity and the benefits of the proposed control strategy, a specific load-case PI computation is presented 
hereafter. Figure 10 shows the Bode plots of the open-loop system (in green) and the closed-loop one (in blue), considering the load parameters specified in Table 2.

TABLE II

\begin{tabular}{|l|l|}
\hline Parameter & Value \\
\hline $\mathrm{R}_{\mathrm{m}}$ & $100 m \Omega$ \\
\hline $\mathrm{L}_{\mathrm{m}}$ & $700 \mu \mathrm{H}$ \\
\hline
\end{tabular}

We can observe how the closed-loop plot flattens the gain of the system, increases its bandwidth and does not present the characteristic peak at the resonant frequency of the open-loop system.

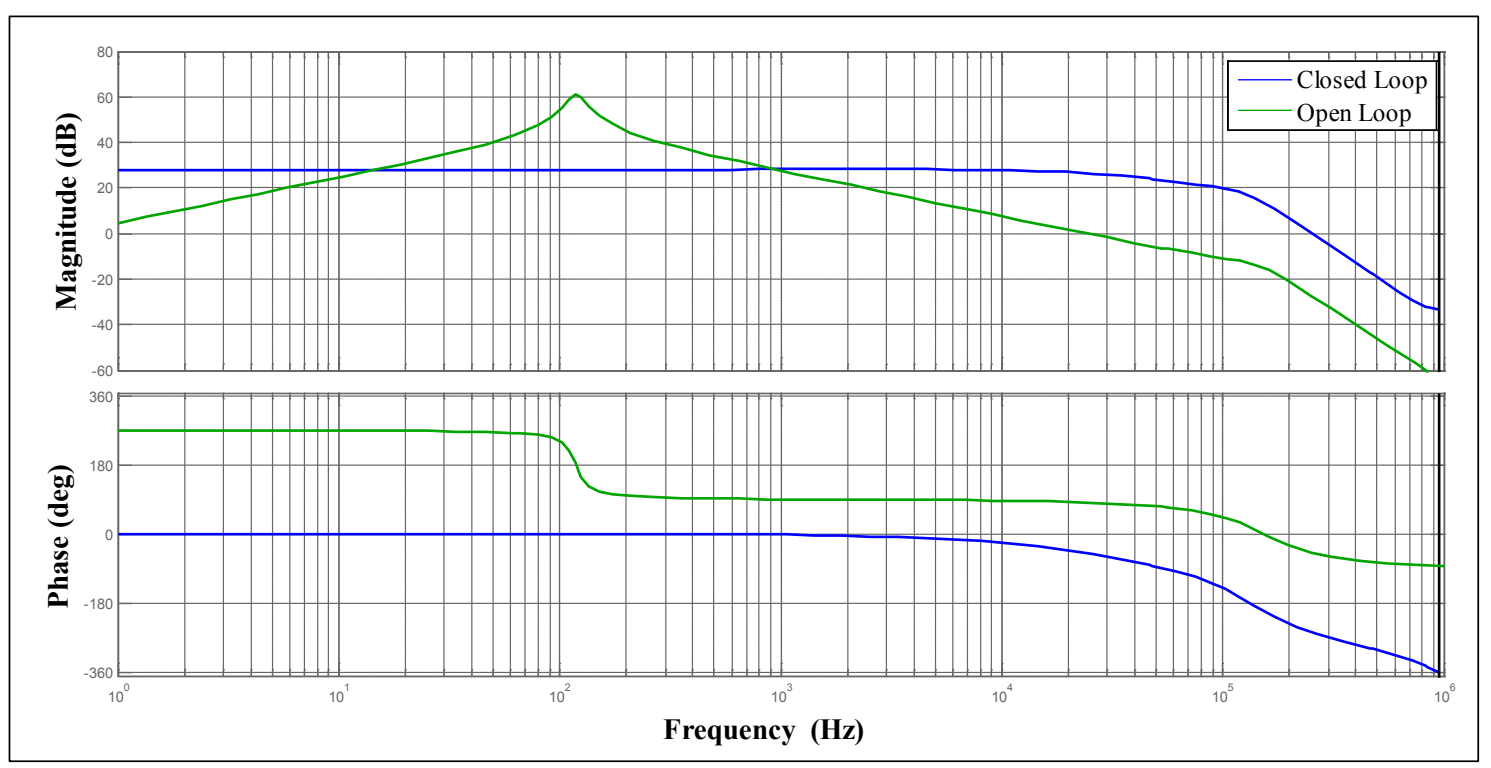

Fig. 10: Open-loop and closed-loop control systems bode plots.

\section{Digital Implementation and measurements}

The load current measurement is performed using a high precision DCCT with $250 \mathrm{kHz}$ bandwith. The magnet current and the capacitor bank voltage are acquired using two 16-bit ADCs operating at 1MSPS. The analogue actuation is performed using a 14-bit 40MSPS DAC. The control algorithm is mapped into a Spartan 6 FPGA from Xilinx. In order to reduce the transients at the beginning of the pulse and to minimize the magnet current settling time, the initial conditions of the controller are computed according to the load resistance and magnet current reference value before the triggering of the pulse. These initial conditions are then applied at the controller output when the flat-top current value is detected. The output H-brigde is controlled by the FPGA based board that is synchronised with a higher level supervision system that allows the synchronisation with the particle beam and the operation of the accelerator complex.

\section{Experimental Results}

At CERN, these converters are used to supply different magnet types that are mainly quadrupoles. Their inductance and resistance values exhibit large variations so as their operational current and flattop duration requirements. The experimental results displayed below are obtained with the load parameters given in Table II. 


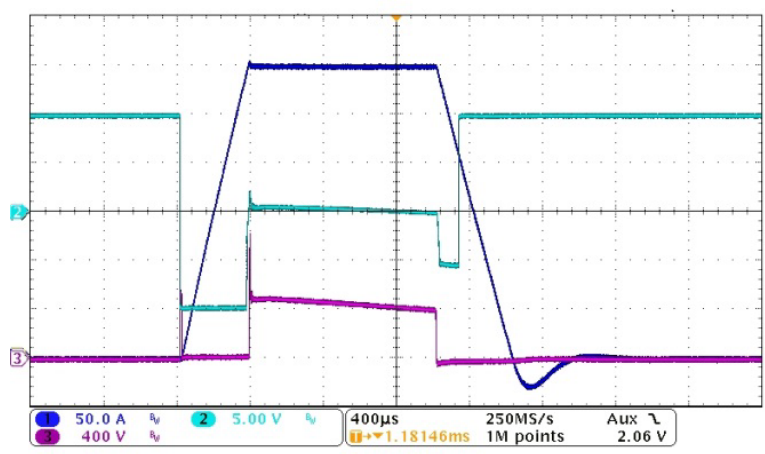

(a)

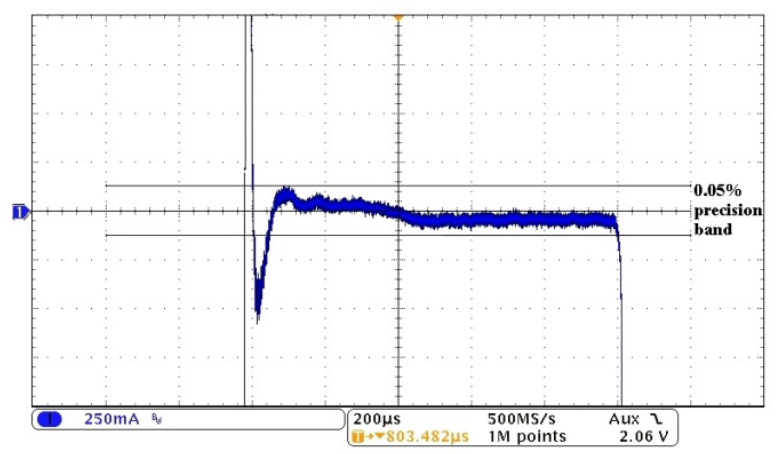

(b)

Fig. 11: Experimental waveforms during the pulse with 300A current reference [Output current (dark blue), IGBT $V_{C E}$ voltage (purple) and $V_{c e}$ ref $D A C$ actuation (light blue)] (a) and magnified flat-top output current (b)

Figure 11 shows a pulse of $300 \mathrm{~A}$ and $1 \mathrm{~ms}$ flat-top duration. In this case, the capacitor charging voltage $V_{C}$ is set to $600 \mathrm{~V}$. The current ramps to $300 \mathrm{~A}$ in $400 \mu \mathrm{s}$, and the flat-top settling time is about $100 \mu \mathrm{s}$. The precision of the current during the flat-top is $4 \times 10^{-4}$ of the reference value.

\section{Conclusion}

This document has investigated the control of high power IGBT modules in the ohmic region for fast pulsed power applications. The IGBT power module has been modelled at different operating points showing high gain and dynamics variations. Consequently, a specific IGBT driver operating in voltage closed-loop has been implemented, allowing the linearization of the IGBT static parameters and the stabilization of its dynamics. The transfer function of the IGBT module and its closed loop driver has been identified and the associated current control system has been designed to achieve zero steadystate error and a fast transient response. The proposed control system has been implemented using an FPGA based regulation board. Finally, experimental results fulfilling the operational requirements have been presented.

\section{References}

[1] J.M. Cravero, C. De Almeida Martins, R.G. Retegui, N. Wassinger, M. Benedetti: A new multiple-stage converter topology for high power and high precision fast pulsed current sources, 13th European Conference on Power Electronics and Applications, EPE '09.

[2] E. Dallago, G. Venchi, S. Rossi, M. Pullia, T. Fowler, and U. Nielsen: The power supply for a medical synchrotron beam chopper system, Proc. 34th Annual Conf. of IEEE Industrial Electronics IECON 2008, pp. 1016-1020.

[3] J.M. Cravero, J.P. Royer: The IGBT as an element of switch discharge with a linear mode use in capacitor discharge power converters, EP2 Forum 98, Electrical Power Technology in European Physics Research, ESRF, Grenoble, pp. 139-145.

[4] P. R. Palmer and J. C. Joyce: Circuit analysis of active mode parasitic oscillations in IGBT modules, IEE Proceedings Circuits Devices and Systems, Vol.150, No. 2, pp.85-91.

[5] P.R. Palmer, H.S. Rajamani: Active Voltage control of IGBTs for high power applications, IEEE Transactions on Power Electronics, vol.19, no.4, pp. 894- 901.

[6] Y. Wang, P.R. Palmer, A.T. Bryant, S.J. Finney, M.S. Abu-Khaizaran, L. Gangru: An Analysis of HighPower IGBT Switching Under Cascade Active Voltage Control, IEEE Transactions on Industry Applications, vol.45, no.2, pp.861-870. 